\title{
LA EXPERIENCIA BOLIVIANA Y LA ORGANIZACIÓN \\ COMUNITARIA Y COOPERATIVA EN EL MARCO DE LA \\ ECONOMÍA PLURAL
}

Gabriel Loza Telleria ${ }^{1}$

\section{Resumen/Abstract}

El autor sostiene que, a diferencia de lo que postula el Modelo de Economía Plural, el proceso de avance en la realidad boliviana es desigual, dado que, por una parte, se ha centrado en la nacionalización y en las empresas públicas, y, por otra, se asienta en la forma de organización cooperativa en el sector minero y en el sector informal de la economía, relegando la economía solidaria, en un contexto con alta desprotección social, informal y capitalista. No se observan avances en un socialismo comunitario, puesto que el peso y la importancia de la comunidad campesina se ha mantenido relativamente igual con relación a los gobiernos anteriores, salvo la economía campesina de la coca, basada en pequeños propietarios y escasa tradición comunitaria.

Palabras clave: Economía Social Solidaria, Economía Plural, Nacionalismo, Empresas Públicas

\section{THE BOLIVIAN EXPERIENCE AND THE COMMUNITY AND COOPER ATIVE ORGANIZATION WITHIN THE FR AMEWORK OF} THE PLURAL ECONOMY

The author argues that, unlike what postulated Model Plural Economy, the process advance in the Bolivian reality is uneven, since on the one hand, has focused on nationalization and public enterprises, and, on another, sits in the form of cooperative organization in the mining sector and the informal sector of the economy, relegating the solidarity economy, in a context with high social, informal and capitalist vulnerability. No progress has been made in a community socialism, since the weight and importance of the peasant community has remained relatively unchanged compared to previous governments, except the peasant coca economy based on small landowners and little community tradition.

Keywords: Social Solidarity Economy, Plural Economy, Nationalization and Public Companies

1 Boliviano, Universidad Católica Boliviana. E-mail: engabolo@hotmail.com

Recibido el 17/05/2016. Aceptado el 10/05/2016 


\section{Introducción}

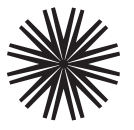

De las cinco partes que componen la actual Constitución Política del Estado Plurinacional de Bolivia (CPE), a diferencia de anteriores, dedica una cuarta parte a la estructura y organización económica del estado, conformada por dos Títulos y 103 artículos. En el título I de organización del estado, en el Artículo 306, señala claramente: "El modelo económico boliviano es plural".

No obstante, ello, han surgido al interior del propio Gobierno diversas interpretaciones que apuntan a que el proceso de cambio tiene por objetivo la construcción del socialismo comunitario, pese a que la economía comunitaria es solamente mencionada una sola vez en el artículo 306 de la CPE en la parte relativa a principios. Así, por ejemplo, en la opinión de Rada (2014), el objetivo estratégico del actual proceso debe ser la construcción del Socialismo Comunitario y García Linera (2015), habla de una "nueva economía comunitaria naciente" y que "tiene la llave del futuro", el cual será, necesariamente "un tipo de socialismo comunitario", distinto a la sociedad y la economía capitalista.

Todos estos aspectos justifican la necesidad de analizar las características Modelo de Economía Plural aplicado en Bolivia, ${ }^{3}$ en el contexto de la problemática de laEconomía Socialy Solidaria, para encontrar que en la realidad hubo un proceso de avance desigual con tendencia a la organización estatal, que pone en cuestión su vigencia. Para tal efecto, en primer lugar, a manera de marco general se presenta el concepto y los principios de la economía plural según la Constitución Política del Estado Plurinacional y la interpretación dominante del Socialismo Comunitario. Con base en la concepción del Modelo de Economía Plural, se examinan los avances efectivos, especialmente en la organización económica estatal y la organización cooperativa minera y, en menor medida, en la organización económica comunitaria. Se termina con las perspectivas, las cuales tienden a consolidar este avance desigual, que posterga a la economía comunitaria, quedando la economía solidaria desprotegida y limitada al sector informal.

3 Un análisis detallado se encuentra en Loza (2013), Bolivia. El modelo de Economía Plural. 


\section{Marco general de la economía plural}

\section{El concepto de Economia Plural}

La Constitución es muy específica sobre el Modelo de Economía Plural, definiéndola claramente, en el Artículo 306, como constituida por las formas de organización económica comunitaria, estatal, privada y social cooperativa, las cuales a su vez pueden a su vez constituir entre sí empresas mixtas.

Estrictamente, la CPE define la economía plural en función del régimen de propiedad, como el caso de la forma de organización estatal y privada, correspondiendo a la vez a las llamadas formas de organización comunitaria y social cooperativa un régimen de propiedad privada, en última instancia, aunque esta no sea individual ni divisible, sino asociativa, donde los beneficios se reparten entre los miembros de la comunidad o de la cooperativa.

En la manera como se organiza la producción y la distribución de su producto es que lo comunitario y lo asociativo se diferencian de la forma estrictamente privada. Por tanto, la economía plural es un tipo de economía mixta desde el punto de vista de la propiedad de los medios de producción y de su participación en el mercado. Adicionalmente, la propia CPE permite la constitución de empresas mixtas entre las diferentes formas de organización (Cuadro 1). 


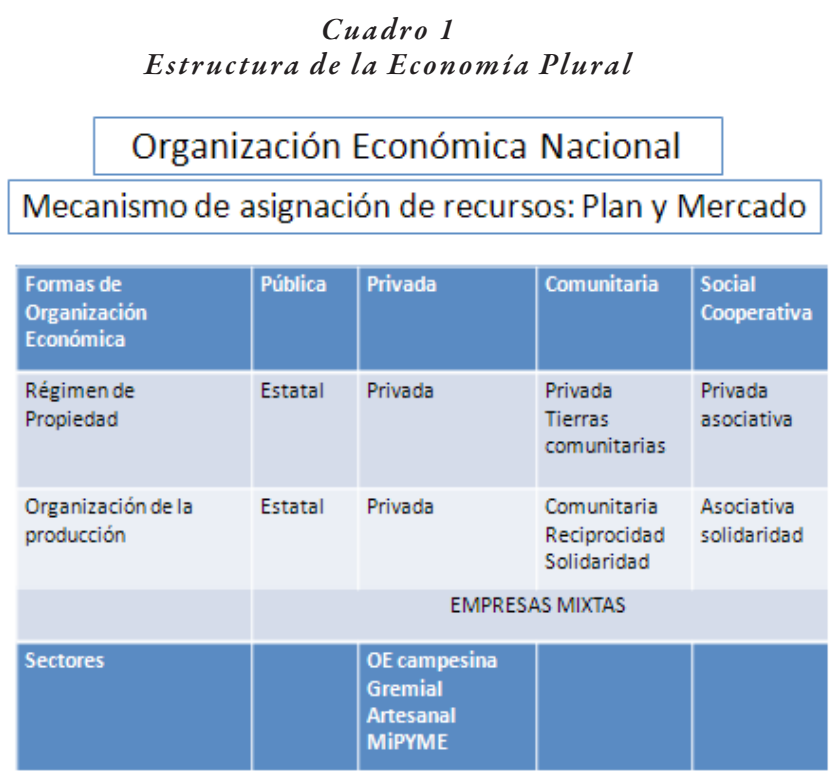

Fuente: Elaboración propia con base en la CPE.

Nota: MiPYME; micro, pequeña y mediana empresa.

Adicionalmente, la Constitución dentro de la Sección IV de Políticas Sectoriales, señala que el Estado protegerá y fomentará a los siguientes sectores:

- Organizaciones económicas (OE) campesinas y las asociaciones de organizaciones de pequeños productores urbanos y artesanos.

- El sector gremial, el trabajo por cuenta propia y el comercio minorista.

- La producción artesanal.

- Las micro, pequeñas y medianas empresas productoras, urbanas y rurales.

Menciona a la organización económica campesina, como si fuera diferente a la organización comunitaria, aunque se refiere a ella como parte de los sectores beneficiados con políticas económicas sectoriales, en función del tamaño de la unidad productiva. Las asociaciones de pequeños productores, el sector gremial, artesanal y la micro y pequeña empresa, en la práctica, forman parte del sector informal de la economía boliviana.

Por último, la CPE, en el Artículo 313, define una "organización económica nacional”, que tiene los siguientes propósitos de carácter: 
- Generación del producto social.

- La producción, distribución y redistribución justa de la riqueza y del excedente económico.

- La reducción de las desigualdades de acceso a los recursos productivos.

- La reducción de las desigualdades regionales.

- El desarrollo productivo industrializador de los recursos naturales.

- La participación activa de la economía pública y comunitaria en el aparato productivo.

En esta disposición la Constitución menciona a la "economía” pública y comunitaria, pero solo en cuanto a su participación en el aparato productivo.

Por otra parte, la CPE establece a la planificación como el mecanismo de asignación de recursos, pero no prohíbe el mecanismo de mercado puesto que ni lo menciona. Establece que el gobierno debe presentar el Plan de Desarrollo Económico y Social a la Asamblea Legislativa Plurinacional (Art. 172), el carácter integral y participativo de la planificación: (Art. 316) y dispone que el estado garantizará la creación, organización y funcionamiento de una entidad de planificación participativa que incluya a representantes de las instituciones públicas y de la sociedad civil organizada (Art 317).

\section{Principios: interés individual versus interés social}

La visión de la economía plural no es un enfoque basado en la hegemonía del capitalismo, la propiedad privada y el libre mercado salvaje ni tampoco es un enfoque basado exclusivamente en la lucha de clases y el socialismo estatista, sino es una visión pluricultural, plurinacional y anticolonial.

Diferencia claramente entre liberalismo (individualismo) y colectivismo (estatismo), puesto que establece muy claramente que "la economía social y comunitaria complementará el interés individual con el vivir bien colectivo" (Art. 306). Además, establece los principios de esta coexistencia o convivencia entre las distintas formas de organización económica, como son los principios de complementariedad, reciprocidad y solidaridad, distinta a los modelos solamente basados en el principio de la competencia.

El concepto de "economía social y comunitaria", por tanto, aparece en la CPE referida no a las formas de propiedad ni mecanismos de asignación de recursos, sino estrictamente referida a los principios y valores. Sería equivalente a una "ascesis puritana "o "espíritu" como Max Weber decía del capitalismo, 
definiéndolo como aquellos hábitos e ideas que favorecen el comportamiento racional para alcanzar el éxito económico.

El concepto de desarrollo inmerso en el Plan Nacional ${ }^{4}$ y que esta sintetizada en la frase Vivir Bien, está más relacionado con el enfoque del "otro desarrollo" de la economía social y solidaria (Gráfico 1). El concepto del Vivir Bien tiene dos motivaciones simultáneas: el lograr el acceso y disfrute de los bienes materiales junto con la realización afectiva, subjetiva y espiritual. Este enfoque se alinea con el de Amartya Sen (2000), quien criticó el enfoque neoliberal del bienestar material individual (utilitarismo) que conducía automáticamente al bienestar social y nacional y que solo ponía énfasis en el acceso a bienes y servicios. Postula, por el contrario, que el acceso a bienes y servicios es un medio para alcanzar un plan de vida o una realización individual plena.

El concepto de Vivir Bien plantea además que el acceso material y la realización individual se sujeten a dos condiciones; armonía con la comunidad y armonía con la naturaleza.

Gráfico 1

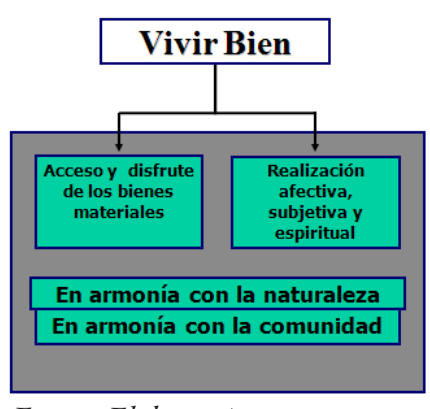

Fuente: Elaboración propia

con base en el Plan Nacional de

Desarrollo (2006-2011).

La elección colectiva trata de la estrecha relación entre objetivos de la política social y las aspiraciones y preferencias de los miembros de una sociedad. Este enfoque permite superar el conflicto entre valores individuales y elección social.

4 Publicado en la Gaceta Oficial de Bolivia (2007). 


\section{Socialismo Comunitario}

Antes y después de la nueva CPE se postuló un "socialismo comunitario como alternativa al capitalismo" como plantea Samanamud (2010), o la economía social y comunitaria como "formación económica, contenido, sentido y direccionalidad de la economía plural" como conceptualiza Prada (2010). El núcleo de esta propuesta sería entonces una lógica económica no capitalista, centrada en el valor de uso, reapropiación social del excedente y reproducción ampliada de la sociedad, es decir como alternativa a la lógica capitalista, valor de cambio, apropiación privada del excedente y acumulación capitalista ampliada.

El Socialismo Comunitario en García Linera (2010: 7 y 8), señala que "La nueva Constitución define un proceso largo al final del cual está el socialismo comunitario que, previamente tiene que atravesar un período de transición" y que "cuando hablamos de socialismo comunitario, hablamos de algo distinto, podemos llamarle comunitarismo o buen vivir, pero en el fondo estamos hablando de algo distinto a la sociedad capitalista".

De Alarcón (2010: 1), señala que el concepto de socialismo comunitario "generalmente se entiende que se trata de forma de socialismo -lo que en sí mismo precisa ya una definición- pero lo comunitario suele quedar en abstracción" ..." El tema de la ambigüedad en la definición, no es, sin embargo, un tema casual. Al ser una realidad a construir, el socialismo comunitario no tiene un contenido específico, previamente determinado o, si se quiere, es un concepto a construir". No obstante, concluye: "En su carácter más genérico y esencial, podría pensarse que el socialismo comunitario es la forma que asume la lucha contra el capital teniendo como horizonte y como medio de realización las formas comunitarias". (De Alarcón, 2010: 10)

De Alarcón (2010: 15), con base en el, pensamiento del Vicepresidente Álvaro García Linera señala que:

“... la condición material, que no es sino el potenciamiento de las formas productivas comunitarias y por formas productivas comunitarias estamos entendiendo no sólo a las comunidades agrarias sino a todas aquellas estructuras que contengan notas de la forma comunidad en el ámbito urbano (esquemas asociativos familiares, barriales, zonales, sectoriales, etc.). Queda claro que las formas comunitarias, aun en el marco del dominio y vigencia del 
capitalismo, aun subsumidas al capital, conllevan en su interior tendencias emancipadoras. Potenciarlas desde el Estado, formular políticas para multiplicarlas en todo el territorio nacional es contribuir a crear la condición material no sólo de la destrucción del Estado sino de la liberación del trabajo”.

Lo comunitario para García Linera (1988) es el germen del socialismo, de acuerdo con lo que concluye De Alarcón (2010: 4):

"Pero, en todo caso, lo que más importa de las 3700 comunidades censadas en 1950 no es tanto la forma de propiedad de la tierra, sino el trabajo cooperativo y combinado, que posibilita. Esto es lo que más le importa a Marx y, en general, lo que más importa a las condiciones de la Revolución Socialista en el país, pues ese trabajo colectivo y combinado- podrá convertirse en la base de la producción y apropiación colectiva que representa el socialismo”.

A diferencia de la izquierda tradicional, sostiene que, para llegar al socialismo, no es necesario pasar por la disolución de la comunidad y que la potencialidad de la comunidad radica en el carácter del trabajo que desarrolla. El salto cualitativo en la formulación de García (2009), es contraponer la forma civilizatoria del valor, propia del capitalismo, a la forma comunidad, que no es sino la proyección del ayllu universal como nueva forma de socialidad.

Recientemente García Linera (2015: 3-4) hizo algunas apreciaciones señalando que "socialismo...es la vieja economía capitalista aún mayoritaria, asediada por la nueva economía comunitaria naciente" y que "en el socialismo coexisten muchas formas de propiedad...Pero que hay solo una propiedad y una forma de administración de la riqueza que tiene la llave del futuro: la comunitaria”.

\section{La participación del estado en la economia y el sector privado}

\section{El tamaño del estado en la economía}

Medir la presencia del estado en la economía no es una tarea fácil y mucho más hacerlo comparable con otros países. Se podría utilizar el PIB por el lado del gasto y obtener la importancia o tamaño del consumo y la inversión pública. Así, para 2013 la incidencia del Consumo Público fue de 13,9\% del 
PIB y por el lado de la Formación Bruta de Capital se estima una participación del 10,4\% de la Inversión Pública, lo que da un 24,2\% del PIB, solo superior en 2 puntos porcentuales al nivel del gasto en 2005 que fue de $22,1 \%$.

La otra forma seria medir la presencia del estado en la actividad económica, pero el Instituto Nacional de Estadísticas (INE) no diferencia entre empresas públicas y empresas privadas, por lo que una estimación gruesa, suponiendo la presencia estatal en hidrocarburos (4\%), en minería y metalurgia $(1,6 \%)$, en transportes $(3,5 \%)$, electricidad $(0,5 \%)$ en comunicaciones $(0,5 \%)$ y en los servicios financieros $(0,4 \%)$, daría un $12,4 \%$, de presencia estatal directa para 2013.

Otro indicador se refiere al peso de las empresas públicas en el gasto fiscal total. Así, el total del gasto de las empresas nacionales respecto al PIB en 2013 fue de 30,4\%, después de subir desde 1,3\% en 2005. Sin embargo, llama la atención el mayor componente del gasto corriente (27,2\% del PIB) en comparación al gasto de capital (3,2\% del PIB).

\section{El comportamiento de la inversión pública, privada nacional y extranjera}

El rol de la inversión pública en el desarrollo económico es uno de los factores que diferencia el modelo actual del modelo neoliberal que privilegió la inversión directa extranjera (IDE), incluso en desmedro de la inversión privada nacional. En la literatura económica hubo un marcado sesgo en contra de la inversión pública y además era más fácil de contraer o cortar que el gasto corriente en los programas de ajuste estructural.

En el periodo 2006-2013 subió la participación de la inversión pública en el PIB, de $8,1 \%$ a $11,3 \%$, se recuperó moderadamente la IDE de un $2,4 \%$ a $5,9 \%$ en 2013, pero se observa una declinación de la inversión privada nacional de un 3,8\% en 2006 a 1,9\% en 2013. La gran diferencia está en la composición total de la inversión (Gráfico 2). 


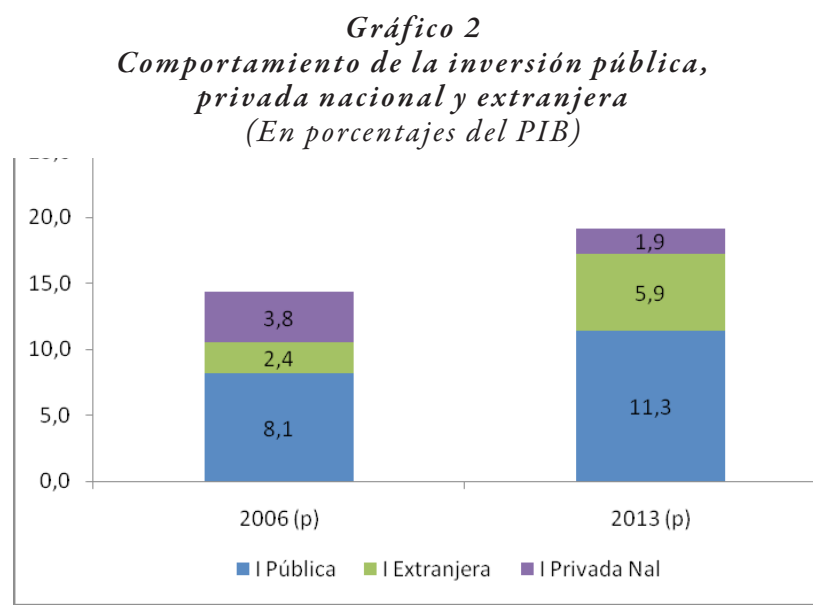

Fuente: Elaboración propia con datos del INE y del Banco Central de Bolivia.

La IDE que había tenido en 1999 una participación en el total invertido de 63,6\% cae en 2013 a un 30,9\%, en cambio la inversión pública aumentó en 16 puntos porcentuales hasta representar el 59,3\% de la inversión, mientras que la inversión privada nacional de una baja incidencia llegó a representar un $9,8 \%$ del total en 2013.

\section{La tendencia a la nacionalización y estatización}

A partir de 2006, con el Gobierno del Presidente Evo Morales, se profundiza el proceso de nacionalización de los hidrocarburos. Así, mediante DS 28701, de mayo de 2006, se establece que las empresas petroleras están obligadas a entregar en propiedad de Yacimientos Petrolíferos Fiscales Bolivianos (YPFB) toda la producción de hidrocarburos. Se nacionalizan las empresas Chaco S.A, Andina S.A, Transredes SA, Petrobras Bolivia Refinación SA y Compañía. Posteriormente se nacionaliza la Compañía Logística de Hidrocarburos Boliviana S.A y la empresa AIR BP Bolivia SA ABBSA.

Se amplía la nacionalización al sector minero con la Empresa Huanuni, se autoriza a la Corporación Minera de Bolivia (COMIBOL) a participar en toda la cadena productiva minera, se nacionaliza el Complejo Metalúrgico Vinto y el Centro Minero de Colquiri. En el sector de energía eléctrica se nacionalizaron las empresas de electricidad en Cochabamba (ELFEC), La Paz (Electropaz), en Oruro (ELFEO) y la Empresa Transportadora de Electricidad (TDE). En el servicio de agua, la empresa Aguas del Illimani y en 
telecomunicaciones la Empresa Nacional de Telecomunicaciones (ENTEL) y, por último, la nacionalización de los Servicios Aeroportuarios Bolivianos (SABSA).

En 2013, la inversión de las Empresas Públicas fue de \$US 994,9 millones, $25,6 \%$ por encima del registrado en 2012 , representando el $26,3 \%$ de la inversión total. La inversión realizada por este nivel institucional es el que viene dando impulso a la inversión en el área productiva. En 2005, en valor era de \$US 98 millones y representaba el 16,3\% de la inversión pública total.

En la gestión 2005, sólo 6 empresas públicas nacionales estaban en operación, con la nacionalización y la mayor participación del estado en la economía; en 2013 el número de empresas en operación llegó a 23, distribuidas en diferentes rubros, como hidrocarburos, minería, energía eléctrica, comunicaciones, alimentos, textiles y servicio aéreo, entre otros. De las 23 empresas públicas, 11 presentan utilidades, pero el $95 \%$ del total de utilidades corresponde a la empresa de YPF.

\section{La economía comunitaria y la economía plural}

La Nueva Constitución establece que el estado promoverá y protegerá la organización económica comunitaria, que comprende los sistemas de producción y reproducción de la vida social, basada en los principios y la visión de "las naciones y pueblos indígena originario y campesinos" (Art. 307).

En los diferentes trabajos sobre el tema comunitario se habla de comunidad, economía y empresa comunitaria en forma indistinta, sin embargo, es mejor precisarla como forma de organización económica, y más propiamente tal como un régimen de propiedad, como plantean Muñoz y Chiroque (2009).

Lo comunitario visto como una sociedad y una economía aparecen como alternativa al capitalismo, mientras como forma de organización económica ha coexistido y combinado desde la colonia, junto con formas feudales como las haciendas, y con formas capitalistas de producción. Ha adoptado diversos elementos del mercado, como los precios y utilidades, por lo que prácticamente no sería una alternativa al capitalismo sino funcional al sistema. Según la Fundación Tierra (2013: 20): "El mercado se ha convertido en el principal factor que determina tanto el uso de la tierra como los patrones de consumo alimentario, indistintamente del tipo de propiedad de la tierra". 
Sin embargo, no están claras las dificultades para su relacionamiento al exterior de la comunidad, como señalan Muñoz y Chiroque (2009), porque una cosa es adecuarse a la lógica del capitalismo y otra a la lógica del mercado. Entendiendo que, según Núñez del Prado (2009: 4) “intercambio mercantil y mercado son instituciones económicas previas al capitalismo y no equivalentes a la teología y fundamentalismo de mercado, lo que el capitalismo y la modernidad se apropiaron haciendo creer que es privativo y exclusivo de sus estructuras".

En el sentido estricto, la forma de organización comunitaria es históricamente una forma de producción de la economía campesina localizada en el ámbito rural, en que combina formas de propiedad privada familiar con usos comunitarios. Combina un uso privado y acumulación del excedente con la redistribución de este excedente por diversos mecanismos generados principalmente a través del mercado.

En los avances en la gestión del Presidente Evo Morales está la Ley 144 de la Revolución Productiva Comunitaria Agropecuaria, en la cual define la Economía Comunitaria:

"Constituye un modelo de desarrollo que comprende sistemas de planificación, organización, producción, generación de excedentes y su distribución para el bienestar común; basado en la cosmovisión de los pueblos indígena originarios campesinos, comunidades interculturales y afro bolivianas, quienes administran su territorio, recursos y tienen sus propias formas de organización en armonía y equilibrio con la Madre Tierra."

Con esta definición la confusión sobre economía comunitaria se amplifica al constituirla como modelo de desarrollo, que es un concepto mucho más amplio que abarca políticas de desarrollo, y al asociarla con la planificación, que es un mecanismo de asignación de recursos. Lo más curioso es que no menciona las relaciones con el mercado, solamente la distribución del excedente para el bien común y no sobre su destino para uso familiar o privado.

Adicionalmente con el Articulo 8 de la Ley 144 se introduce un nuevo concepto, el de Organizaciones Económicas Comunitarias (OECOM), constituidas en el núcleo orgánico, productivo, social y cultural para el vivir bien, que en los hechos es una ampliación del concepto inicial indígena originario campesino a las comunidades interculturales y afro bolivianas. 
Otro avance es la Ley 300, del 15 de octubre de 2012, "Ley de la Madre Tierra y Desarrollo Integral para Vivir Bien". Plantea que la Madre Tierra debe generar desarrollo para el pueblo boliviano de manera integral (Artículo 2 y 7.); por tanto, los derechos colectivos de indígenas, originarios y campesinos, los derechos individuales y los derechos de la Madre Tierra son considerados "interdependientes y complementarios". Propone la "eliminación de la concentración de la propiedad de la tierra o latifundio y otros componentes en manos de propietarios agrarios y empresas, para que se logre una mayor equidad en el acceso a los beneficios de la madre tierra con énfasis en el soberanía y seguridad alimentaria.

Por último, están los avances en materia de Saneamiento y Titulación de Tierras, las que han sido significativos durante el Gobierno del Presidente Morales con relación a las gestiones entre 1996-2005: tres veces en el monto de hectáreas tituladas, cinco veces en beneficiarios y diez veces en títulos emitidos. Un dato interesante es que antes solamente el $10 \%$ de las mujeres accedían a la tierra, ahora acceden un 46\%, aunque la Fundación Tierra, en Colque et al (2016), señala que la superficie de estas tierras es muy baja.

Si se analiza el avance en el proceso de titulación de las tierras por tipo de propiedad se observan dos periodos. Entre 1953 y 1993, el 40\% de los títulos fueron para las empresas, el $21 \%$ para la propiedad comunitaria y un $9 \%$ para la pequeña propiedad. Entre 2010-2014 cambió a un 13,9\% para las empresas, un $27,3 \%$ para la propiedad comunitaria, un $14,1 \%$ para la pequeña propiedad y $44 \%$ para las Tierras Comunitarias de Origen (TCO), según Colque et al (2016: 175).

Por tanto, entre 1996-2015 la estructura de la tenencia de la tierra cambió; $10 \%$ para empresas, $26 \%$ para campesinos e interculturales, $14 \%$ para las Tierras Comunitarias de Origen (TCO) de Tierras Altas y para las TCO de Tierras Bajas el 17\%, con un total de las TCO de $31 \%$, quedando un $33 \%$ para tierras fiscales (Gráfico 3). ${ }^{5}$

5 La Disposición Transitoria Séptima de la CPE establece que la categoría de Tierra Comunitaria de Origen (TCO) se sujetará a un trámite administrativo de conversión a Territorio Indígena Originario Campesino. 


\section{Estructura de la Tenencia de la Tierra 1996-2015 (en millones de hectáreas)}

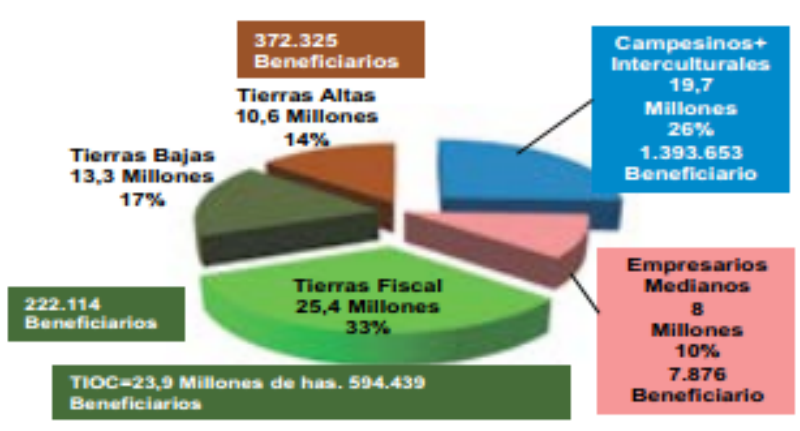

Fuente: Extraido del Ministerio de Comunicación (2016).

Es decir, ha habido un cambio estructural en materia de titulación de tierras, el que ha dado lugar, en 2015, a un cambio en la estructura de la tenencia de la tierra, con un $57 \%$ del total en propiedad de los pequeños productores y comunidades de Tierras Altas y Bajas, disminuyendo las tierras de las empresas privadas y aumentando las tierras fiscales.

Sin embargo, de acuerdo al INE (2015), el Censo Agropecuario 2013 muestra que: "De 34.654.983,7 hectáreas que las UPA (Unidad de Producción Agropecuaria) tienen o trabajan, 84,1 por ciento está bajo el régimen de tenencia en propiedad; 13,0 por ciento, cedida por la comunidad; 1,4 por ciento, en arriendo; 1,2 por ciento, cuidada y 0,3 por ciento, al partir o "partido".

La crítica de la Fundación Tierra es, que la denominada segunda versión de la reforma agraria boliviana, ha cumplido una parte meritoria de su cometido, pero su continuidad, encarnada y reducida a un simple registro catastral de tierras, no solo es redundante sino regresiva como se concluye en Colque et al, (2016: 224).

Siendo en la práctica difícil de operacionalizar el concepto de economía comunitaria, es más conveniente utilizar el concepto de 'agricultura campesina e indígena', como lo hace la Fundación Tierra (2013): "para referirnos a aquellas unidades productivas agropecuarias operadas por familias que están débil pero crecientemente conectadas al mercado de productos agrícolas y precariamente al mercado laboral". Sin embargo, reconoce la heterogeneidad de sectores que 
comprendería, puesto que abarca: "campesinos parcelarios de las tierras altas, pequeños ganaderos tradicionales, originarios de ayllus y markas, indígenas de tierras bajas, campesinos cruceños, colonizadores andinos, entre otros".

Un indicador de la importancia de la economía campesina es la participación del sector agropecuario en el Producto Interno Bruto (PIB). La participación del sector ha ido disminuyendo de $10,9 \%$ en 2006 a $10 \%$ en 2013. El subsector más importante es la producción agrícola no industrial, más asociada al occidente del país, cuya participación disminuyó de 5,1\% en 2006 a 4,8\% del PIB en 2013 y si se le añade el subsector de la producción de coca, que de $0,39 \%$ en 2006 subió a $0,44 \%$ en 2013, se tiene una participación del $5,2 \%$ del PIB para 2013, menor al 5,5\% en 2006. En términos de la ocupación por actividad económica, la agropecuaria en su conjunto concentra el $33,9 \%$ de la ocupación total.

En síntesis, la economía campesina con formas de producción comunitaria y familiar tendría máximo una incidencia del 5,2\% del PIB, similar a la economía agropecuaria del oriente, muestra una mayor integración al mercado y realiza un proceso de acumulación del plus producto en el contexto de una economía capitalista. En el censo agropecuario, la forma de tenencia de la tierra muestra que $84,1 \%$ está bajo el régimen de tenencia en propiedad y solo un $13,0 \%$ es cedida por la comunidad.

\section{Los roles y la participación de la producción cooperativa}

De acuerdo con la Declaración sobre la Identidad Cooperativa de la ACI y la Recomendación sobre la promoción de las cooperativas de la OIT, 2002 ( $\left.\mathrm{N}^{\circ} 193\right)$, una cooperativa es: "una asociación autónoma de personas unidas voluntariamente para satisfacer sus necesidades y aspiraciones económicas, sociales y culturales en común a través de una empresa de propiedad conjunta, y de gestión democrática". Se regula de acuerdo con 7 principios operacionales, a saber: "adhesión voluntaria y abierta; gestión democrática por parte de los socios; participación económica de los socios; autonomía e independencia; educación, formación e información; cooperación entre cooperativas, e interés por la comunidad". Se basa en los "valores cooperativos de autoayuda, responsabilidad personal, democracia, igualdad, equidad y solidaridad, y una ética fundada en la honestidad, transparencia, responsabilidad social e interés por los demás" (CICOPA, 2014: 16). 
En 1993 se creó la Confederación Nacional de Cooperativas de Bolivia (CONCOBOL), y según ella: "A la fecha el impacto del sector cooperativo en la economía del país es de aproximadamente un tercio del PIB, de igual manera casi un tercio de la población del país participa en alguna cooperativa". Sin embargo, no existe ni un censo ni una base de datos del total de cooperativas en el país. El Gobierno del, Presidente Evo Morales mediante Ley General de Cooperativas 356 de abril de 2013 establece en su artículo 1:

"La presente Ley tiene por objeto regular la constitución, organización, funcionamiento, supervisión, fiscalización, fomento y protección del Sistema Cooperativo en el Estado Plurinacional de Bolivia, en sujeción a las disposiciones de la Constitución Política del Estado".

Señala en su Artículo 5 que "La organización económica social cooperativa forma parte de la economía plural y es de interés del Estado Plurinacional, su fomento y protección, para contribuir al desarrollo de la democracia participativa y justicia social". En el Artículo 6 establece los siguientes principios cooperativos: solidaridad, igualdad, reciprocidad, equidad en la distribución, finalidad social y no lucro.

En el artículo 8 dispone que: "Las aportaciones de las asociadas y los asociados, a las cooperativas, consistentes en efectivo, bienes, derechos y/o trabajo, constituyen propiedad colectiva. El instrumento de trabajo podrá ser de propiedad individual" y en el artículo 14 establece que "Las cooperativas adoptarán el régimen de Responsabilidad Limitada R.L”.

En síntesis, la organización económica de las cooperativas se basa en la propiedad privada con formas de gestión asociativa o de cooperación y un uso del excedente económico por parte de los socios de la cooperativa.

Debido a limitaciones de información, se examinará el sector financiero y minero. En el sector financiero la presencia de las cooperativas y de mutuales en el caso boliviano tiene alta importancia comparado con otros países. Las cooperativas financieras y mutuales tienen una participación relativa del 6,8\% del total de depósitos, el $8,3 \%$ de la cartera y un poco más alta su peso respecto al patrimonio, de 13,2\%. Esta participación por ejemplo es similar en cuanto a depósitos y cartera respecto al banco estatal, el Banco de la Unión, aunque es mayor respecto al patrimonio de acuerdo con la Autoridad de Supervisión del Sistema Financiero-ASFI (2014). La Federación Nacional de Cooperativas de 
Ahorro y Crédito tiene un total de 160 cooperativas con 280 mil socios.

La CPE con relación a las cooperativas, dispone que se promueva su organización en actividades de producción. Señala que el estado será responsable de las riquezas mineralógicas que se encuentren en el suelo o subsuelo cualquiera sea su origen, y su aplicación será regulada por la ley. Se reconoce como actores productivos, a la industria minera estatal, industria minera privada y sociedades cooperativas" (Art. 369-I).

Las estadísticas generadas por la Federación Nacional de Cooperativas Mineras (FENCOMIN) muestran un alto potenciamiento del cooperativismo minero, sobrepasando en la actualidad los 65,000 socios y socias cooperativistas, organizados en 11 federaciones departamentales y regionales.

Como explica Michard (2008), inicialmente las cooperativas comprendían a los trabajadores mineros excluidos de la minería estatal y privada, pero posteriormente se desarrollaron, correspondiendo actualmente a dos tipos de modelos. Por un lado, se tiene a las cooperativas grandes, con yacimientos importantes, que aglutinan a varios miles de socios, trabajadores subcontratados, y equipos auxiliares que han logrado acceder a cierto tipo de tecnología y eliminar varios intermediarios, vinculándose directamente con los compradores. Por el otro lado, se encuentran las cooperativas pequeñas con pocos socios que trabajan directamente la mina, con tecnología muy precaria, que deben subalquilar maquinaria y comercializar su pequeña producción mediante una serie de intermediarios.

La importancia de la cooperativa minera se muestra en el Cuadro 2. En términos de empleo el número de trabajadores aumentó, pero su participación relativa disminuyó de $90,2 \%$ a $87,8 \%$, debido a la presencia de la minería estatal, que, de una participación nula en 2003, aumentó a 6\% del total del empleo en 2013. Al igual que en caso de las exportaciones, que en términos absolutos aumentó de 85,4 a 660,6 millones de dólares entre 2003 y 2013, pero en términos relativos disminuyó, debido al aumento de la presencia estatal de prácticamente cero a $8,9 \%$ de las exportaciones mineras. 
Número de trabajadores y millones de dólares

\begin{tabular}{lrrrr|rrrr}
\hline & \multicolumn{3}{c|}{2003} & \multicolumn{4}{|c}{2013} \\
Actores & Trabajadores & PP\% & Exportaciones & PP\% & Trabajadores & PP\% & Exportaciones & PP\% \\
\hline Estatal & 117 & 0,2 & 0,0 & 0,0 & 7902 & 6,0 & 273,3 & 8,9 \\
Mediana Privada & 5212 & 9,4 & 283,9 & 76,9 & 8110 & 6,2 & 2149,3 & 69,6 \\
Cooperativas & 49950 & 90,2 & 85,4 & 23,1 & 114920 & 87,8 & 660,6 & 21,5 \\
Total & 55357 & 100,0 & 369,3 & 100,0 & 130932 & 100,0 & 3076,9 & 100,0 \\
\hline
\end{tabular}

Fuente: Elaboración propia con datos del Ministerio de Minería y Metalurgia (2014) y Banco Central de Bolivia.

Es un sector que ha recibido el apoyo del Gobierno del Presidente Morales pese a ostentar niveles de riqueza y utilidades en un proceso explícito de acumulación capitalista basada en sobreexplotación de los trabajadores no socios. Además, las cooperativas mineras suscribieron 42 contratos de asociación con empresas privadas nacionales y trasnacionales, de los cuales "las cooperativas sólo pagan al Estado el 1\% de sus ganancias, mientras que las empresas privadas obtienen el $80 \%$ de las utilidades y la cooperativa se queda con el 19\%". ${ }^{6}$ En 2009 el gobierno creó el FOFIM, fondo minero de inversión en apoyo a las cooperativas mineras De los tres impuestos mineros que todas las empresas mineras pagan: la regalía minera, impuesto a las utilidades de las empresas (IUE) y la alícuota adicional al Impuesto a las Utilidades de las Empresas, las cooperativas solo pagan las regalías mineras (\$US 31,8 millones equivalente al 23,6 del total de regalías mineras), estando exentas de los otros impuestos por su "carácter social" como lo estipula la Constitución Política del Estado. El problema es determinar si cumplen esa función social para tener acceso a prerrogativas.

\section{Las perspectivas de la Economia Social, Solidaria, Cooperativa y Comunitaria}

El objetivo del proceso de cambio, como dice la CPE, no es eliminar la propiedad privada y construir solamente una propiedad estatista ni tampoco con base en la economía comunitaria campesina constituir un socialismo comunitario, sino de articular una coexistencia y complementariedad entre las distintas formas de propiedad con un rol de dirección del estado, el cual a

6 Declaraciones del Ministro de Gobierno publicadas por Correo del Sur.com. Lunes 7 de abril de 2014. 
su vez debe promover la integración y articulación de las diferentes formas de organización económica.

En un sentido restringido, es una economía predominantemente privada desde el punto de vista de la participación del PIB, puesto que la economía pública tendría un peso de $12,4 \%$ y la economía comunitaria -familiar una participación de solamente 4,8\% del PIB, y la cooperativa un 4\%. En cambio, el $79 \%$ corresponderá a la formación económica privada propiamente tal.

Cuadro 3

Indicadores de la Economía Plural: 2013

(En porcentajes)

\begin{tabular}{|lrrr|}
\hline Organización & PIB & Empleo & Exportaciones \\
\hline Estatal & 12,4 & 4,2 & 53,3 \\
Comunitario & 4,8 & 22,0 & 0,0 \\
Privado & 78,8 & 77,3 & 41,6 \\
Cooperativa & 4,0 & 2,5 & 5,1 \\
\hline Total & 100,0 & 100,0 & 100,0 \\
\hline
\end{tabular}

Fuente: Elaboración propia con datos del INE y del BCB:

Con referencia a las exportaciones totales hubo un cambio estructural puesto que en 2005 el 3\% correspondía a empresas estatal y el 97\% al sector privado, mientras que, en 2013 , el $53 \%$ corresponde a empresas públicas, $5 \%$ cooperativas y el $42 \%$ a la empresa privada.

El cambio se da en las exportaciones de hidrocarburos al ser totalmente realizadas por $\mathrm{YPFB}$, puesto que en la minería el $90 \%$ corresponde a la empresa privada y en las exportaciones no tradicionales la casi totalidad al sector privado, excluyendo las exportaciones de castaña de la Empresa Boliviana de Almendras EBA.

En términos de empleo, un proxy basado por el peso de la economía campesina tendría un $22 \%$ de la población ocupada, la cooperativa un $2,5 \%$ y el sector público (200 mil funcionarios en 2013), un 4,2\% del empleo total, lo cual muestra que el sector privado participaría con el $77 \%$ de la población ocupada.

Por tanto, tanto en términos de incidencia en el PIB, exportaciones como en el empleo, la organización económica privada es la más importante de la economía plural. 
La tendencia en la gestión pública ha sido fortalecer la organización económica estatal y en el sector minero el sesgo fue hacia las cooperativas mineras en cuanto a tratamientos preferenciales en materia de otorgación de yacimientos, obligaciones tributarias y créditos financieros. En política económica, la comunidad campesina ha continuado con su peso específico y no se observan cambios estructurales, con excepción de la reciente Ley de Servicios Financieros que tiene por objetivo una mayor inclusión financiera del área rural. El sector privado ha continuado en buenas relaciones institucionales con el gobierno, existe una nueva Ley de Inversiones que tiene por objeto regular las inversiones extranjeras y establecer un tratamiento preferente a las inversiones nacionales privadas y públicas. La política laboral ha sido favorable con el trabajador formal sobre todo en materia de política salarial, con reajustes periódicos del salario mínimo y de incrementos anuales en el salario y en el establecimiento de un segundo aguinaldo.

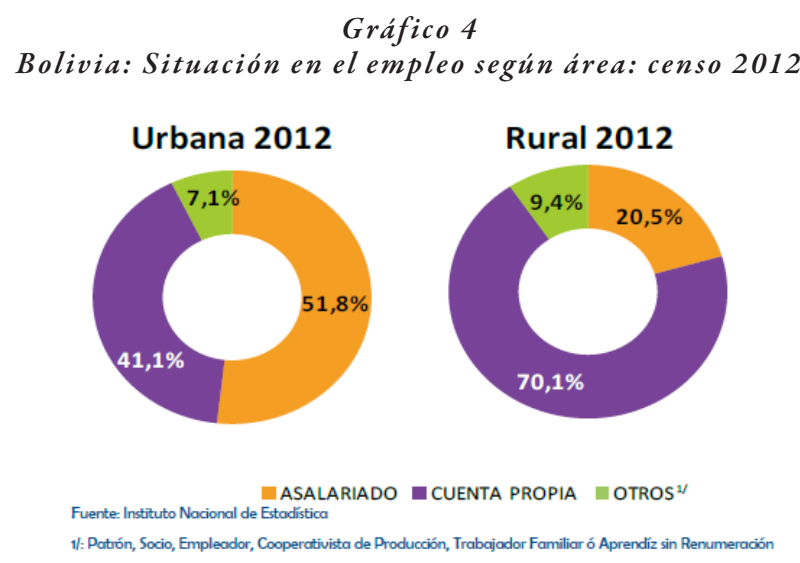

Fuente: Instituto Nacional de Estadística

El problema en Bolivia es la fuerte incidencia del trabajador por cuenta propia; $41 \%$ en el área urbana, siendo el sector "otros", donde está una mezcla de actividades desde el patrón, socio, empleador, cooperativista, trabajador familiar y aprendiz, un 7,2\%, da un total de $48 \%$ de la población ocupada, quedando la categoría de asalariado un 51,8\% (Gráfico 4). El problema del asalariado es que solamente la mitad está incorporada a la actividad formal con beneficios sociales y seguridad social. Así solo un $25 \%$ de la población urbana está en una caja de salud pública y un $12 \%$ en seguro privado. 
El sector informal urbano en Bolivia tiene mucha importancia económica y política. Se estima en un 65\% del empleo urbano en 2011, según CEDLA (2012), y comprende:

- Trabajadores por cuenta propia: unipersonales y familiares

- Propietarios de las micro y pequeñas unidades económicas (hasta 5 ocupados)

- Trabajadores dependientes: operarios, ayudantes, aprendices

- Familiares no remunerados

- Trabajadores a domicilio

- Subcontratados

Este sector está al margen de la política tributaria, aunque a través de la microfinanzas tiene acceso al sistema financiero. Tiene una forma de organización asociativa, que le permite formar parte de lo que en Bolivia se denomina Movimientos Sociales, que le facilita participar en las diferentes instancias políticas. Si bien, por un lado, se le llama como parte de la "economía popular y solidaria", por otro lado, es un sector con alta desprotección social e inestabilidad laboral y con el objetivo del lucro y la acumulación del capital.

En síntesis, el proceso de avance de la Economía Plural es desigual, por una parte, se ha centrado en la nacionalización y la conformación de empresas públicas, es decir en la organización económica estatal. Por otra parte, se asienta en la forma de organización cooperativa en el sector minero y en el sector informal de la economía, cuyas asociaciones forman parte de los Movimientos Sociales y tienen un peso político en el Gobierno y en el Movimiento al Socialismo.

No se observan avances hacia un socialismo comunitario, el peso de la comunidad campesina se ha mantenido relativamente igual, el sector que ha ganado participación es la economía campesina de la coca, basada en pequeños propietarios y escasa tradición comunitaria. 
Referencias Bibliográficas

ASFI (2014). Principales variables del Sistema Financiero. Noviembre. La Paz.

CEDLA (2012). Estadisticas sector informal urbano en Bolivia: 2010-2011. La Paz.

CICOP (2014). Cooperativa y Empleo: un informe mundial. Desjardins. COOP.

Colque Gonzalo, Tinta Efraín y Sanjinés Esteban (2016). Segunda Reforma Agraria: una historia que incomoda. Fundación Tierra. Segunda Edición. La Paz.

De Alarcón Silvya (2010). "Socialismo Comunitario". Bolivian Research Review. Vol. 8. October-November 2010. La Paz

Fundación Tierra (2013). ¿Comer de nuestra tierra? Informe 2012. La Paz.

García Linera Álvaro (2015). Socialismo Comunitario del Vivir Bien. Discurso del Vicepresidente Álvaro García Linera en el Acto de Posesión Presidencial. Enero. La Paz.

(2010), "El Socialismo Comunitario", Revista de ANALISIS. Año 3-Número 5. Vicepresidencia del Estado.

(2009). Forma valor y forma comunidad. Muela del Diablo Editores. Clacso. La Paz.

(1988). Las condiciones de la revolución socialista en Bolivia. A propósito de obreros, aymaras y Lenin. La Paz: Ediciones Ofensiva Roja.

Gaceta Oficial de Bolivia. Decreto Supremo 29272 de 12 de septiembre de 2007. Plan Nacional de Desarrollo (2006-2011).

Instituto Nacional de Estadísticas INE (2015). Censo Agropecuario 2013. Bolivia. La Paz.

Instituto Nacional de Estadísticas INE (2014). Datos relevantes del Censo de Población y Vivienda 2012. La Paz. 
Instituto Nacional de Reforma Agraria (INRA) (2012). Estado de Saneamiento y Titulación de Tierra. Octubre. MDRyT. La Paz.

(2010). La tierra vuelve a manos indigenas y campesinas. Enero. La Paz.

Ley General de Cooperativas. Ley 356 de abril de 2013. La Paz.

Ley de la Madre Tierra. Ley 300 del 15 de octubre de 2012. La Paz.

Ley de Revolución Productiva Comunitaria Agropecuaria. Ley 144 del 26 de junio de 2011.La Paz.

Loza Gabriel (2013). Bolivia. El modelo de Economia Plural. Vínculos. La Paz.

Michard, Jocelyn (2008). Cooperativas mineras en Bolivia. Centro de Documentación e Información Bolivia. Cochabamba. CEDIB.

Ministerio de Economía y Finanzas Públicas MEFP (2014). Memoria de la Economía Boliviana 2013. La Paz.

Ministerio de Minería y Metalurgia (2014). Estadísticas del sector minero y metalúrgico: 1980-2013. La Paz.

Ministerio de Comunicación del Estado Plurinacional de Bolivia (2016). Informe Presidencial 2006. 2016. La Paz.

Morales Manuel (coord.), Gianotten Vere, Devisscher Marc y Pacheco Diego (2012). Hablemos de Tierras. Consultora Sur. Plural. INRA. La Paz.

Muñoz Sandra Chiroque Henry (2009), "La economía comunitaria de la nación aymara”. Otra Economía. Volumen III. No 5-Segundo semestre.

Núñez del Prado José. (2009). Economias Indigenas: Estados del arte desde Bolivia y la economía política. CIDES. La Paz.

Prada Raúl (2010), "Más allá del capitalismo y la modernidad”, en Descolonización en Bolivia. Vicepresidencia del Estado-BDM. La Paz. 
Rada Alfredo. (2014). “Tesis socialista comunitaria”. Diario Página Siete. 7 de septiembre de 2014. La Paz.

Samanamud Jiovanny (2010), "Sobre las problemáticas del Pluralismo Económico", en Descolonización en Bolivia. Vicepresidencia del Estado-BDM. La Paz.

Sen Amartya (2000). Desarrollo y Libertad. Planeta. Buenos Aires. 